\title{
Application of Thermal Images for Determining the Vegetation Coverage Ratio at Free-Frame Shotcrete Grid Beam Protected Slope
}

\author{
Chien-Yuan Chen ${ }^{1}$ and Zheng-Sheng Jiang ${ }^{2}$ \\ ${ }^{1}$ National Chiayi University, Taiwan \\ ${ }^{2}$ Fifth District Maintenance Engineering Department, Highway Administration, Taiwan
}

\begin{abstract}
In this study, infrared thermography was used to determine the vegetation coverage ratio (VCR) at a freeframe shotcrete grid beam-protected slope. An infrared thermal imager can detect the changes in surface radiation temperature on naked and vegetation-covered slope areas. Regional temperature analysis was performed through thermography, and the average temperature derived from the captured thermal images was used as the index for the vegetation area; the VCR was also evaluated. This method can be used in engineering practice after construction to reduce the errors in subjective visual judgment and can also serve as an effective and scientific evaluation methodology. A long-distance noncontact detection method for VCR evaluation can increase the engineering applicability of the proposed method after construction.
\end{abstract}

\section{Introduction}

Mountainous roads pose a challenge in maintaining traffic safety during the rainy season and typhoon events. The focus of expressway maintenance in mountainous areas is on engineering management at the upper and lower slopes. In the face of climate change, regular maintenance and postdisaster reconstruction of mountainous roadways is emphasized for improving the road slope for disaster resistance. With the increasing awareness of natural environment protection and landscaping for scenery enhancement, shotcrete grid beam-protected slopes are a commonly used engineering measure in Taiwan, with advantages such as low cost, short construction time, less earthwork, and high landscaping potential, compared with large-scale engineering measures.

Free-frame shotcrete grid beams are commonly used to protect unstable slopes or for recovery from naked landslides near expressways in mountainous areas. Such beams are suitable for areas with varying levels of topographic steepness. Free-frame shotcrete can protect slopes with vegetation against soil erosion caused by rainfall and landscape planting. In such protection systems, drainage engineering includes a catchwater drain for collecting surficial water to a hillside ditch to reduce the regolith erosion rate.

The construction flowchart for a free-frame shotcrete grid beam-protected slope includes the following steps (Figure 1):

(a).Designing the material compounding ratio and audit,

(b).Executing slope cutting to remove unstable soils and rocks,
(c).Constructing a galvanized wire mesh, establishing anchor bolts, and assembling reinforcement,

(d).Paving sheet PVC at the vegetation area,

(e).Executing shotcrete construction,

(f).Spraying a plant growth medium.

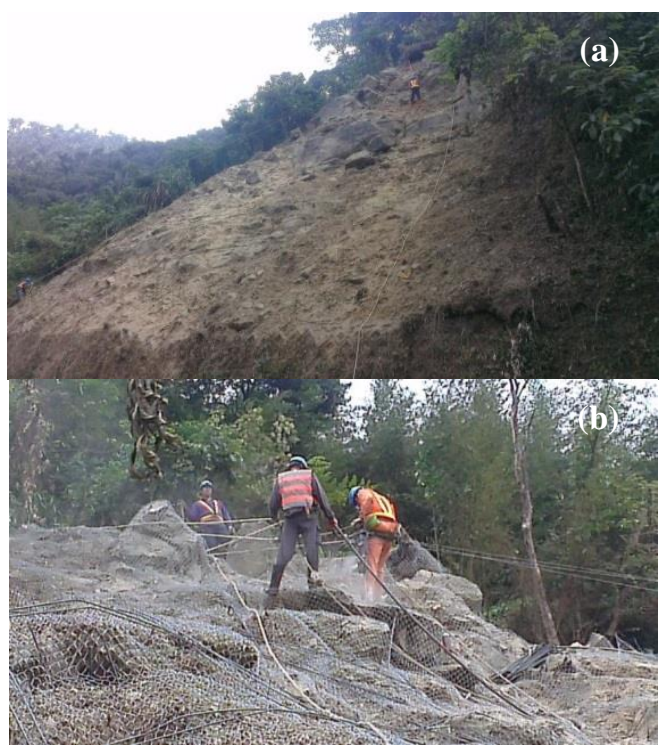




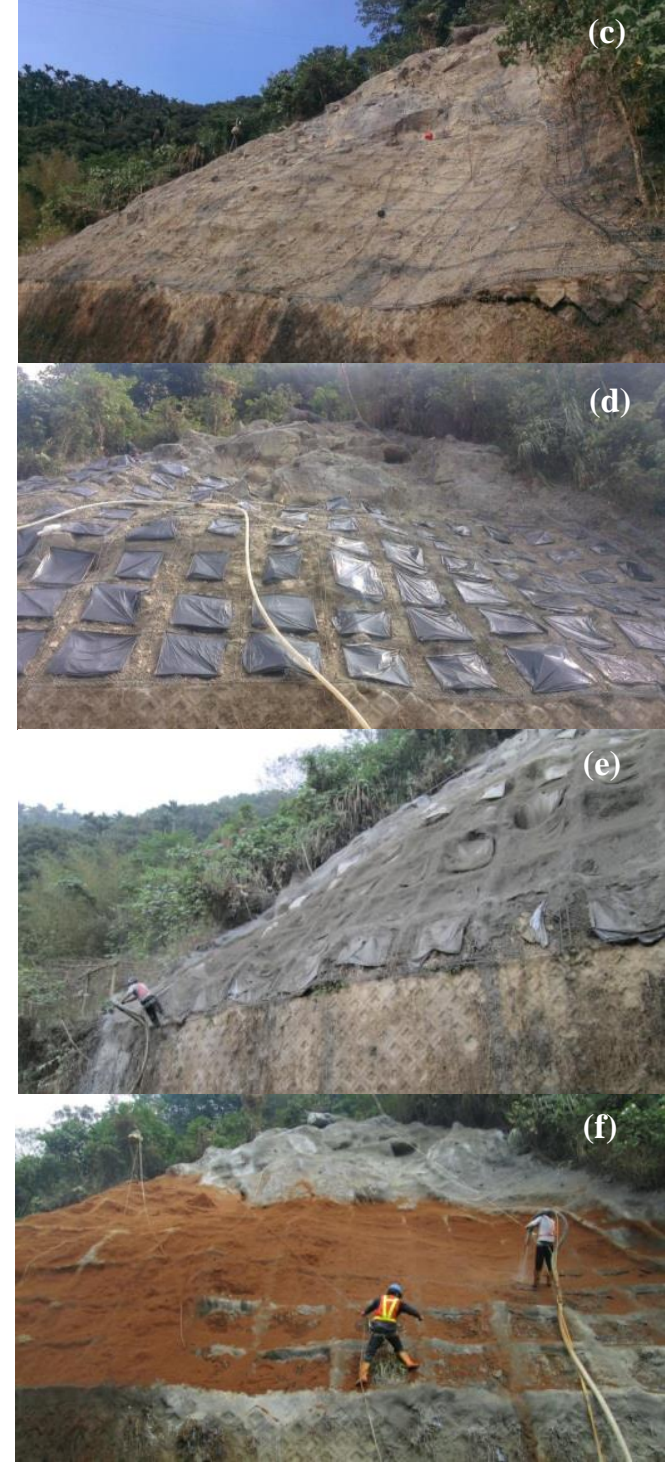

Figure 1. The constructure flowchart for the shotcrete grid beam-free frame protected slope.

The free frame is fixed in size and the shape is flexible to changes in topography. The commonly used free-frame size is $130 \mathrm{~cm} \times 130 \mathrm{~cm}$ along the expressway, and the frame is fixed using anchor bolts. The mix design proportion of the shotcrete material is compounded by cement, sand, and water (Table 1).

Table 1 Mix design proportion of shotcrete material (Directorate General of Highways, MOTC).

\begin{tabular}{ccc}
\hline Material & Unit & Quantity per $100 \mathrm{~m}^{2}$ \\
\hline Cement & $\mathrm{kg}$ & 3800 \\
Sand & $\mathrm{m}^{3}$ & 10.5 \\
water & Liter & 1900
\end{tabular}

The key aspect of a shotcrete grid beam-protected slope is the vegetation cover. In general, the area for spraying the plant growth medium is within the free frame with a size of $95 \mathrm{~cm} \times 95 \mathrm{~cm}$. The size and ruggedness are affected by the steepness and aspect of the slope. During construction, the vegetation coverage ratio (VCR) at the shotcrete site has a major influence on the protection of the slope. The vegetation is typically designed to grow naturally, and the determination of the VCR at the shotcrete site is affected by the topography; thus, visual inspection is commonly performed without any effective quantification methodology.

Thermal images have been applied to various fields for inspection and monitoring. Infrared thermography has been applied to nondestructive testing of concrete and masonry bridges [1] and to anomaly detection in adhesive wall tiling systems [2]. In recent years, thermal images have been widely applied for slope monitoring. Infrared thermography has been used to examine potentially unstable slopes [3,4]. It has also been commonly used for monitoring landslides [5-7] and earth dam failure modes [8]. Similar to a camera, using a thermal imager for monitoring has advantages such as noncontact and longdistance monitoring, and a thermal imager is suitable for both long-term monitoring and short-term inspection of sites with surficial radiation temperature changes.

\section{Material and method}

The monitoring sites in this study were located on Provincial Highway 18, with mileage of $73 \mathrm{~K}+550$ and $73 \mathrm{~K}+980$ (Figure 2). Table 2 lists the coordinates and corresponding area of the protected slope.

Table 2 Locations of the monitoring sites.

\begin{tabular}{|c|c|c|c|c|}
\hline \multirow{2}{*}{$\begin{array}{c}\text { Milage } \\
\text { (start date) } \\
\text { (finish date) }\end{array}$} & \multicolumn{2}{|c|}{$\begin{array}{c}\text { Coordinate } \\
\text { (TWD97) }\end{array}$} & \multirow{2}{*}{$\begin{array}{c}\text { Free } \\
\text { frame } \\
\text { area } \\
\left(\mathrm{m}^{2}\right) \\
\end{array}$} & \multirow{2}{*}{$\begin{array}{c}\text { Grass } \\
\text { species }\end{array}$} \\
\hline & $\mathrm{X}(\mathrm{m})$ & $\mathrm{Y}(\mathrm{m})$ & & \\
\hline $\begin{array}{c}72 \mathrm{~K}+550 \\
(105.11 .29) \\
(106.02 .16)\end{array}$ & $\begin{array}{l}22311 \\
0.383\end{array}$ & $\begin{array}{c}25977 \\
03.256\end{array}$ & 75.16 & $\begin{array}{l}\text { Festuca } \\
\text { arundinacea } \\
, \quad \text { Cynodon }\end{array}$ \\
\hline $\begin{array}{c}73 \mathrm{~K}+980 \\
(101.04 .11) \\
(101.05 .20)\end{array}$ & $\begin{array}{r}22411 \\
1.783\end{array}$ & $\begin{array}{r}25975 \\
92.561\end{array}$ & 473.80 & $\begin{array}{l}\text { dactylon, } \\
\text { Eragrostis } \\
\text { curvula, }\end{array}$ \\
\hline
\end{tabular}

Landslides occurred at the monitoring sites during Typhoon Kalmegi in 2016 and a rainstorm in 2017. Both sides of the slope along Provincial Highway 18 in the mountainous region were naked with a steep gradient and weathered regolith, and were prone to landslides during torrential rainfall. The slope protection engineering process at mileage $72 \mathrm{~K}+550$ was commenced on November 29, 2016, and completed on February 16, 2017, and that at mileage $73 \mathrm{~K}+980$ commenced on April 11, 2012, and completed on May 20, 2012. The vegetation period was 3 months at $72 \mathrm{~K}+550$ and 5 years at $73 \mathrm{~K}+$ 980 to the date of monitoring. The acceptable standard for visual inspection is for a VCR of up to $90 \%$ in Taiwan. The site at mileage $73 \mathrm{~K}+980$ was completed with a VCR of $100 \%$, whereas that at mileage $72 \mathrm{~K}+550$ was naked. The two sites were selected for comparison and further monitoring and analysis. Monitoring was performed using a thermal imager on different dates, and images captured on April 16, 2017, were used for analysis. 

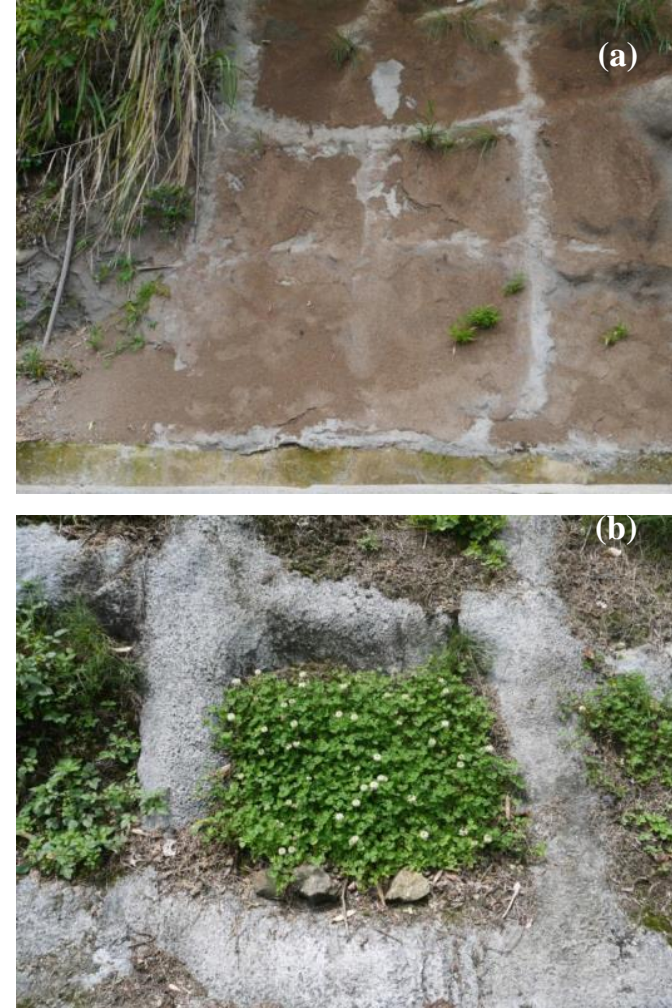

Figure 2. Monitoring site along Provincial Highway 18 at mileage (a) $72 \mathrm{~K}+550$ (b) and 73K + 980 (April 16, 2017).

In this study, the captured thermal images were divided into 36 square grids for the monitoring of radiation temperature changes. The average radiation temperature ( $\mathrm{T}$ in ${ }^{\circ} \mathrm{C}$ ) was measured for each grid corresponding to a different VCR. The thermal imager was used for monitoring the selected sites, and images were captured at different times. A direct linkage between $\mathrm{T}$ and VCR was required to avoid visual adjudgement.

The thermal imager NEC G100D, with an accuracy of $\pm 2{ }^{\circ} \mathrm{C}$ (below $100{ }^{\circ} \mathrm{C}$ ) or $\pm 2 \%$ (above $100{ }^{\circ} \mathrm{C}$ ) and sensitivity of $0.08{ }^{\circ} \mathrm{C}$, was used for the monitoring process. The detector comprises an 8-14 m microbolometer for long waves and 3-5 $\mu \mathrm{m}$ for short waves. The thermal imager can also be used for capturing visible-light digital images with a resolution of 200 megapixels.

\section{Results and analysis}

\subsection{Thermal images for 0\% VCR}

The site at mileage $72 \mathrm{~K}+550$ with a VCR of $0 \%$ was selected for monitoring. The monitoring area could be divided into parts for the plant growth medium and reinforced concrete made of the free frame. Thermal images revealed that the changes in infrared temperature in the area with the plant growth medium were larger than those in the area with free-frame reinforced concerete (Figure 3).

The temperature changes abruptly increased at 11:02 because of sunlight. In general, the average temperature was $42{ }^{\circ} \mathrm{C}$ in the area fully covered from sunlight (shadow area), $43-48{ }^{\circ} \mathrm{C}$ in the area partially covered from sunlight, and more than $50{ }^{\circ} \mathrm{C}$ in the area fully exposed to sunlight. The area partially covered from sunlight had larger infrared temperature changes than the other areas. The infrared temperature was in the range of $40-43{ }^{\circ} \mathrm{C}$ at 13:57 (Figure 4). The overall average infrared temperature for the site with a VCR of $0 \%$ at different monitoring times was $43.39{ }^{\circ} \mathrm{C}$ (Figure 5).
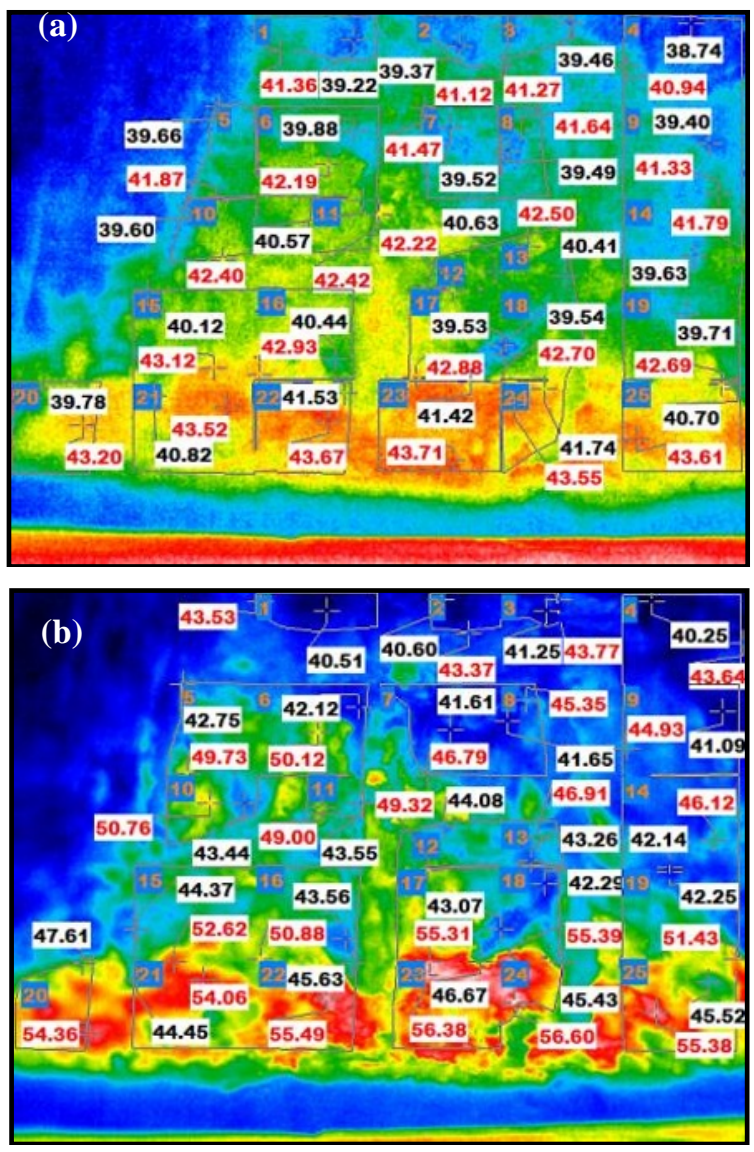

Figure 3. Thermal images for $0 \%$ VCR captured at (a) 11:02 and (b) 13:57 (captured on April 16, 2017).

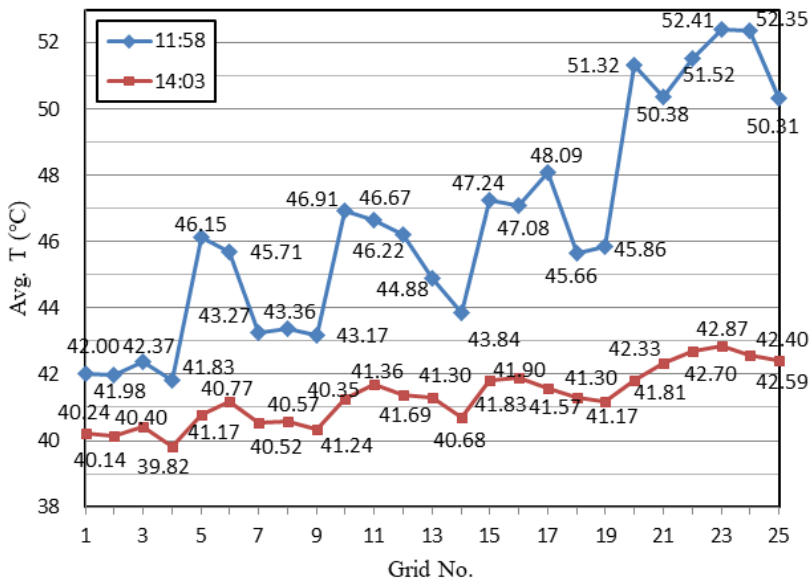

Figure 4. Average infrared temperature changes for $0 \%$ VCR at different grids at 11:02 and 13:57. 


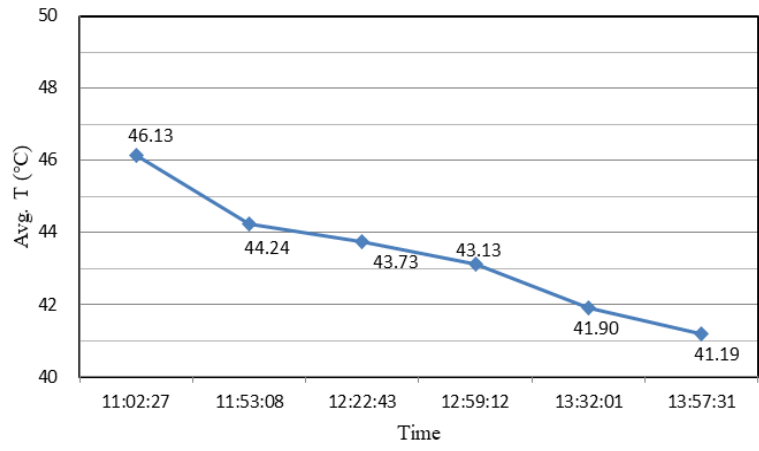

Figure 5. Average infrared temperature changes for $0 \% \mathrm{VCR}$ at different times.

\subsection{Thermal images for $100 \%$ VCR}

The site at mileage $73 \mathrm{~K}+980$ with $100 \% \mathrm{VCR}$ was selected for monitoring at the shotcrete-protected slope. The well-vegetated area showed the lowest infrared temperature, followed by the area with free-frame; the area with a VCR of $0 \%$ had the highest infrared temperature (Figure 6). The overall average infrared temperature was between 43 and $45{ }^{\circ} \mathrm{C}$ at 11:58 and between $40{ }^{\circ} \mathrm{C}$ and $41{ }^{\circ} \mathrm{C}$ at 14:03 (Figure 7). The overall average infrared temperature for the area with a VCR of $0 \%$ at different monitoring times was $46.3{ }^{\circ} \mathrm{C}$ (Figure 8). Two additional sites along the expressway with VCRs of $10 \%$ and $50 \%$ were monitored, and their average infrared temperatures were recorded. Figure 9 shows the regression line for determining the VCR by using thermal images. The data can be regressed as follows:

$\mathrm{T}\left({ }^{\circ} \mathrm{C}\right)=0.286(\mathrm{VCR})+43.25\left(\mathrm{r}^{2}=0.99\right)$

The VCR can be determined by the equation and the average infrared temperature can be monitored using the thermal imager.

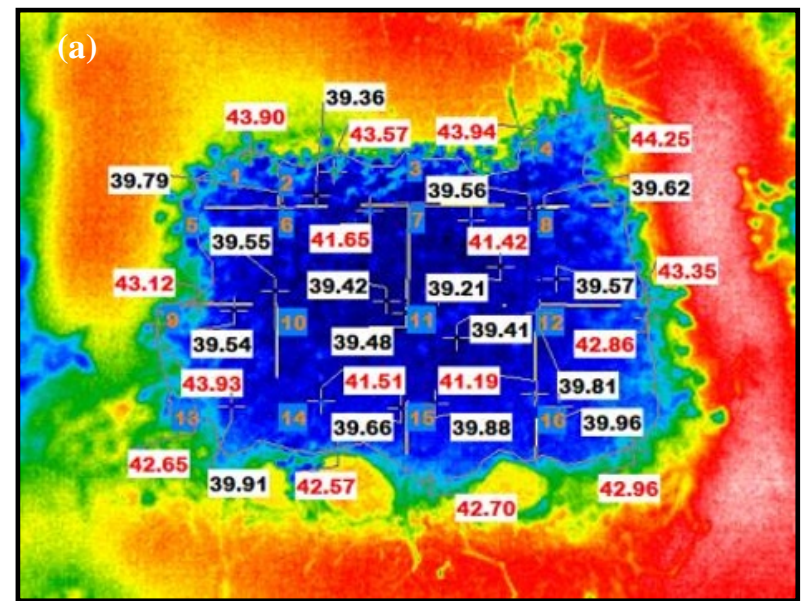

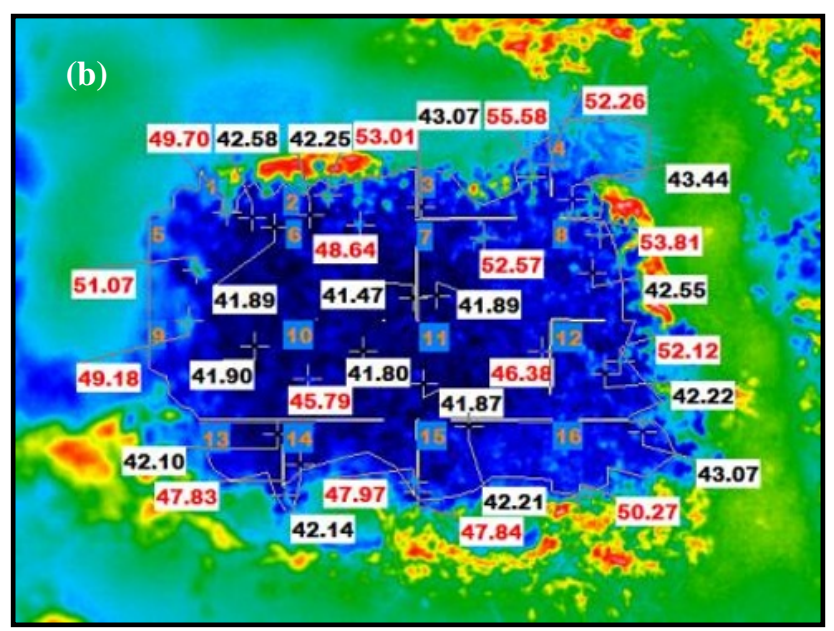

Figure 6. Thermal images for $100 \%$ VCR on (a) 11:58 and (b) 14:03 (captured on April 16, 2017).

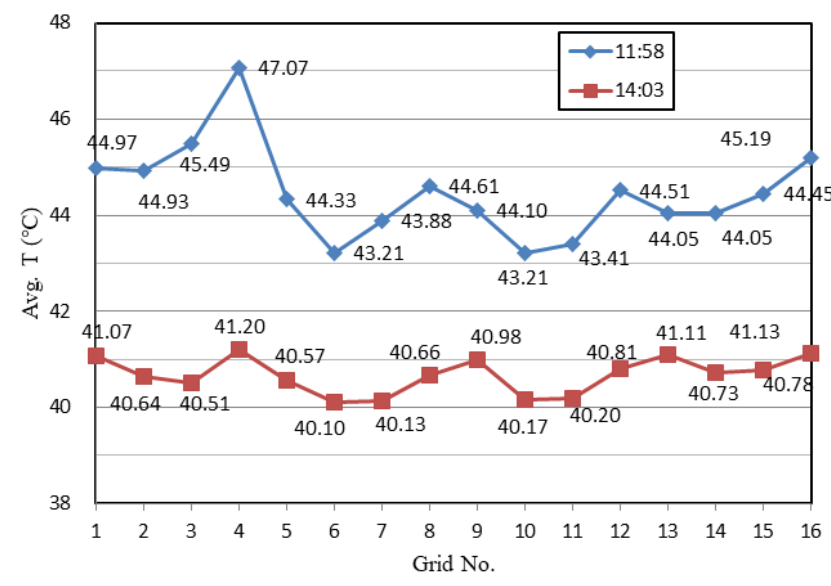

Figure 7. Average infrared temperature changes for $100 \%$ VCR at different grids at 11:58 and 14:03.

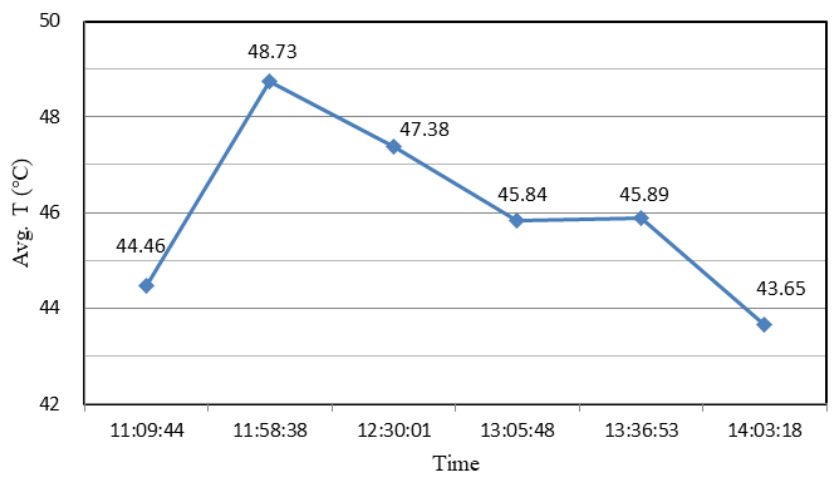

Figure 8. Average infrared temperature changes for $100 \%$ VCR at different time. 


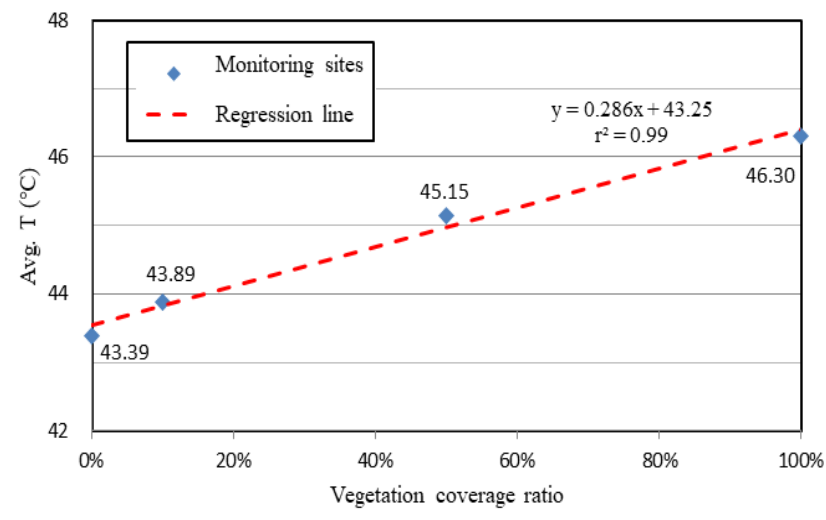

Figure 9. Regression equation for the VCR and average infrared temperature changes at the monitored slope.

\section{Conclusions}

In this study, a thermal imager was used to monitor the VCR at a free-frame shotcrete grid beam-protected slope. The infrared thermal imager could detect the changes in surficial infrared temperature at naked and vegetationcovered areas of the slope. Shotcrete-protected slope areas with VCRs of $100 \%$ and $0 \%$ (naked) were selected for monitoring and analysis. The regional temperature was analyzed through thermography, and the average temperature derived from the thermal images was used as the index for evaluating the VCR. The overall average infrared temperature was used to establish the relationship between the infrared temperature and VCR. An interpolation method was then used to determine the VCR by using the thermal imager. The method can be used in engineering practice after construction to reduce the errors in subjective visual judgment and can also serve as an effective and scientific evaluation methodology.

\section{Acknowledgments}

Authors wishing to acknowledge financial support from Ministry of Science and Technology in Taiwan under contract No. MOST 106-2625-M-415-003.

\section{References}

1. Clark M R, McCann D M and Forde M C 2003 Application of infrared thermography to the nondestructive testing of concrete and masonry bridges NDT International 36 265-275

2. Lourenço T, Matias L and Faria P 2017 Anomalies detection in adhesive wall tiling systems by infrared thermography Construction and Building Materials 148 419-428

3. Baroň I, Bečkovský D and Míča L 2012 Application of infrared thermography for mapping open fractures in deep-seated rockslides and unstable cliffs Landslides 36 265-275

4. Nolesini T, Frodella W, Bianchini S and Casagli N 2016 Detecting slope and urban potential unstable areas by means of multi-platform remote sensing techniques: the Volterra (Italy) case study Remote Sensing 8, 746, doi:10.3390/rs8090746

5. Wu J H, Lin H M, Lee D H and Fang S C 2005 Integrity assessment of rock mass behind the shotcreted slope using thermography Engineering Geology 80 164-173

6. Martino S and Mazzanti P 2014 Integrating geomechanical surveys and remote sensing for sea cliff slope stability analysis: the Mt. Pucci case study (Italy) Natural Hazards and Earth System Sciences 14 831-848

7. Mineo S, Pappalardo G, Rapisarda F, Cubito A and Di Maria G 2015 Integrated geostructural, seismic and infrared thermography surveys for the study of an unstable rock slope in the Peloritani Chain (NE Sicily) Engineering Geology 195 225-235

8. Chen C Y, Chen S C and Chen K H 2016 Earth dam monitoring by using infrared thermography detection Proceedings of Engineering Technology and Innovation 4 40-42 